\title{
HOW A BETTER UNDERSTANDING OF RELATION CAN INCREASE RESPONSIBILITY BETWEEN STAKEHOLDERS?
}

\author{
Bolifraud, Sylvain; Stal-Le Cardinal, Julie \\ École Centrale Paris
}

\begin{abstract}
Construction projects are complex and subject to a lot of conflicts. The misunderstanding between actors is one cause of these conflicts. To understand actor's interrelation is fundamental.

In this paper, we used FAcT Miror method to analyse the relation between the two main actors, Owner and Contractor. Based on the method we built a survey about Fears, Attractiveness and Temptations of treason of each actor, The Miror effect of the method allows us to evaluate what is the thought of an actor about the other and to measure differences between actors' thought on a specific aspect of the relation. Our results allow us to have a better understanding of the relation between Owners and Contractors on a construction project. Moreover, we point out specific aspects of the relation which need to be studied to improve the understanding.
\end{abstract}

Keywords: Human behaviour in design, Complexity, Project management, Construction Project, FAcT Miror

Contact:

Bolifraud, Sylvain

École Centrale Paris

LGI

France

bolifraud.sylvain@gmail.com 


\section{INTRODUCTION}

The thematic of this paper is oriented on the relation between the two main actors of the construction industry, the Owner and the Contractor. The idea that the construction industry has a culture which is opportunistic, prone to conflict and resistant to change is a byword in construction (Rooke, Seymour and Fellows, 2004). In the construction industry, conflict among the contracting parties appears inevitable due to the inherent divergence in interests (Yiu and Cheung, 2006). The basic factors of those conflicts are project uncertainty, contractual problem, and opportunistic behaviour (Mitropoulos and Howell, 2001).

Construction project management is a specific field of project management, according to the production management classification, they enter in the category of unitarian and non-repetitive production. In the construction industry factors like, places where we build the projects, the project itself, contractual elements, clients, and stakeholders, change completely for each new contract. For a worker in the construction industry, the only thing which does not change at each new project is the bag he takes every day to carry his sandwich.

At each new project actors of a construction project have to adapt their processes and their analysis of the counterpart's behaviour. My research question is: Is it possible to find elements of misinterpretation in the relation between the Owner and the Contractor, which are cause of conflicts and could be treated by an improvement of the construction management processes? The final aim of my research is to propose a new method to design processes to avoid the consequences of these errors of interpretation.

Because of cultural differences, legal system differences and the variety of projects it would be exceedingly difficult to achieve an exact statistical study of construction industry's actors' behaviour. The aim of this paper is to outline the general mindset of construction project stakeholders in their relation in the project in this moving environment and to help them to have a better understanding of the other ones.

In this paper responsibility is about the financial aspect of the project. Individuals standing for the different actors manage the budget of the project. To not manage properly the production and contractual processes can lead to major cost overruns and the efficiency of the project can be strongly affected. Moreover, as major projects are most of the time operated by public entities, improving their efficiency is a responsible goal in regards with actual growth rate in western Europe.

The paper is composed of three main parts, first part consists in a state of the art, we define the actors and what are the relations between them in our context, we also review the different methods used to analyse the relation between actors of a project. The second part of our paper presents the chosen method, how we apply it and how we collect the data needed for our analysis. At the end of the section we expose our main results concerning Fears, Attractiveness and Temptation of treason, between actors in construction project. We end our paper with a conclusion opening on possible future works

\section{STATE OF THE ART}

This paper wants to show how improving the understanding of the relation can improve the responsibility from a stakeholder toward another. In the construction industry, the Owner is the party under the contract which agrees to pay for the work, the Contractor is the party responsible for carrying out the works (SCL, 2017). Relation between the owner and the contractor is based on two types of mechanisms, the contractual governance, and the relational governance (Lu et al., 2015). Contractual governance is the formal set of rules of compliance and contracts between transaction partners (Lumineau, Fréchet and Puthod, 2011; Reuer and Arino, 2017) and relational governance illustrate the importance of the relationship between the actors (Poppo and Zenger, 2002) and explains how it allows to minimize transaction costs (Dyer, 1997). Because of bounded rationality, it is not possible to create a complete contract (Brunet, 2005). Also it has been demonstrated that contractual and relational governances function are complementary(Lu et al., 2015).

A lot of research has been conducted to try to understand and to explain how each governance works and how one influences the other and which are the factors implicated in the achievement of a better governance. Most of them use the following step. Authors chose an angle of research, based on a literature review they built a model, and formulate hypothesis, then to test their model and hypothesis, 
they built a survey, and they evaluate their model and their hypothesis to expose validation or limitations.

We see a limitation to these studies, they all try to extract a common view, by analysing the average answer given by the stakeholders of a project. We only find one paper where amongst the data, authors extract a specific sample and analyse the difference of position between Owner and Contractor and find that Owners are greater than Contractors in opportunism(Lu et al., 2015). We think that if there is a distortion between Owner and Contractor views, we should analyse the position of each actor and analyse what they think about the thoughts of the other one.

Another way of seeing the relation between Owner and Contractor is as a cooperative relation. Cooperation is founded on three pillars, contract, communication and trust (Le Cardinal, Guyonnet and Pouzoullic, 1997). Trust has been identified as the most important behavioural factor in managing relationships and can be characterised by three major types, by order of importance; cognition-based trust, system-based trust and, affect-based trust(Wong et al., 2008). The result of the survey conducted by Wong \& al shows that cognition-based trust describes a trusting relationship that builds on mutual understanding through fruitful information exchange and acquaintance.

To analyse the problematic of cooperation, game theory is extensively used, in the prisoner dilemma, two players, who cannot communicate, must choose between two strategies either they cooperate either they don't. Depending of the strategies chosen by each player, the "revenue" of the players is impacted differently, see Figure 1.

\begin{tabular}{|c|r|r|r|}
\hline Player 1 & Cooperation & Non-cooperation \\
\hline Cooperation & & & \\
\hline Non-cooperation & & $\mathrm{r}^{\prime}(=-0,5)$ & \\
\hline
\end{tabular}

Revenues:

$\mathrm{r}, \mathrm{r}$ ': Gain for mutual cooperation

$t, t$ ': Reward for unilateral treason

s, s': Over-loss corresponding to $t$ and t'

$\mathrm{p}, \mathrm{p}$ ': loss in case of non-cooperation

$\mathrm{t}>\mathrm{r}>\mathrm{p}>\mathrm{s}$ and $\mathrm{t}^{\prime}>\mathrm{r}^{\prime}>\mathrm{p}^{\prime}>\mathrm{s}^{\prime}$

Figure 1. Prisoner dilemma illustration

In the prisoner dilemma, players cannot communicate, in a real situation the communication is possible, the "game" can be repeated, and trust becomes a possible strategy.

In this literature review, we see that all methods do not help to reach a better understanding of each position. We do not find studies made on the amelioration of understanding between actors of the relation in construction project. Here after we propose to help build a better comprehension of the relation between Owners and Contractors.

\section{RELATION ANALYSIS}

We see in paragraph 2 that the construction industry has a culture which is opportunistic and conflictual(Rooke, Seymour and Fellows, 2004), the complexity of the project and of the contract are source of incomprehension's. Many factors influence the project and it is common to see unsatisfied obligations, also the length of the project allows the Owner to ask for changes to adapt the project to his evolutive needs and increase the risk of environmental events like adverse weather condition. The consequences are increase of the cost and of the duration of the project, we can give as example the Elbe's Philharmonic in Hamburg, its cost had been multiplied by ten to reach 789 million euros and the construction lasted 10 years instead of the 3 years initially estimated. The normal way to deal with these changes is the claim. A construction claim arises in a contract when one of the parties believes that in some way, by act or omission, the other party does not fulfil its part of the bargain (Levin, 1998; Kartam, 1999). According to experienced professionals, the problem lies in the fact that if parties cannot find an agreement, they risk going through a legal procedure in tribunal or arbitration, which is costly and timely.

\subsection{Methodology used}

Le Cardinal \& al. developed the method FAcT Mirror ${ }^{\circledR}$ (FAcT for Fear, Attractiveness, Temptations) to propose a process that allows to find and frame the interactions between stakeholders in complex situations. The FAcT Mirror ${ }^{\circledR}$ method is particularly adapted (...) for the understanding of 
dysfunction in an interprofessional collaborative group (Le Cardinal, Guyonnet and Pouzoullic, 1997; Le Cardinal et al., 2001). This method is based on communication theory (Watzlawick, HelmickBeavin and Jackson, 1967) and on complex system modelization (Morin, 2005, 2008).

In his PhD thesis, Zimmer (2012), notes that the FAcT Mirror ${ }^{\circledR}$ method answers three needs:

- To establish a diagnostic of a complex problem with all the stakeholders;

- To measure qualitatively and quantitatively the level of the links between stakeholders of a system;

- $\quad$ To produce with all stakeholders an action plan to solve the problem.

The FAcT Mirror ${ }^{\circledR}$ method is based on a listing of the Fears, the Attractiveness ant the Temptations of treason a party can have in a relation with another stakeholder and towards the project itself

Normally the process is based on the organization of workshops where all parties are free to express the FAcT about the relation. After this first phase, all participants are invited to note all the FAcT, the Owner evaluates the importance of its own Fact and he also evaluates the Contractor's FAcT. The notation is based on the security risk assessment system, it means that we combine the probability and the gravity of an item to determine its level of importance

The next step consists in structuring the data by classifying the items by thematic. After grouping in unavoidable thematics based on the Fears, Attractiveness and Temptation, it is possible to draw a new vision of the relation and to find the Danger, the Objectives and the value transgressed. Based on this new shared vision of the relation it is possible to define the action axis and then an action plan to manage the identified subject. Zimmer sums up this process in Figure 2 (Zimmer, 2012).

\begin{tabular}{|c|c|c|c|}
\hline Analysis & Recommendation & Action \\
\hline $\begin{array}{c}\text { Fear } \\
\text { Attractiveness }\end{array} \underset{\text { Temptation }}{\longrightarrow}$ Objective \\
Value
\end{tabular}

Figure 2. FAcT Mirror® road map

\subsection{Application of the method}

In our case, for four reasons it is not possible to reunite the different stakeholders in the same room for a day or more. First reason is availability of the stakeholders, people involved in contract management in construction project are of an important hierarchical level and most of the time, they are overbooked. The second reason is the variety in the organization and contract types of construction projects, to focus on one type of project would have led us to many biases. The third reason is the variety and the number of stakeholders. The fourth reason is the nature of contractual relation in the construction industry, the subject is extremely sensitive, and stakeholders keep secret the negotiations about their disagreements.

The common stakeholders are the Owner, who expresses the need for a new construction and pays for it, the Engineer, who designs the construction and follows the construction process, and the Contractor who builds the construction. Those stakeholders are the three basic actors, but in large and complex project the number of stakeholders can be more important. Figure 3 illustrates the common organization of a construction project; the Owner is the only one party which has contractual link with all the others. The other actors of the relation are of two type, Contractors who realize the works, Designers (Architects and Engineers) and finally Controlling actors which represents external entities and have the role to guarantee that the project is built in respect with regulations. 


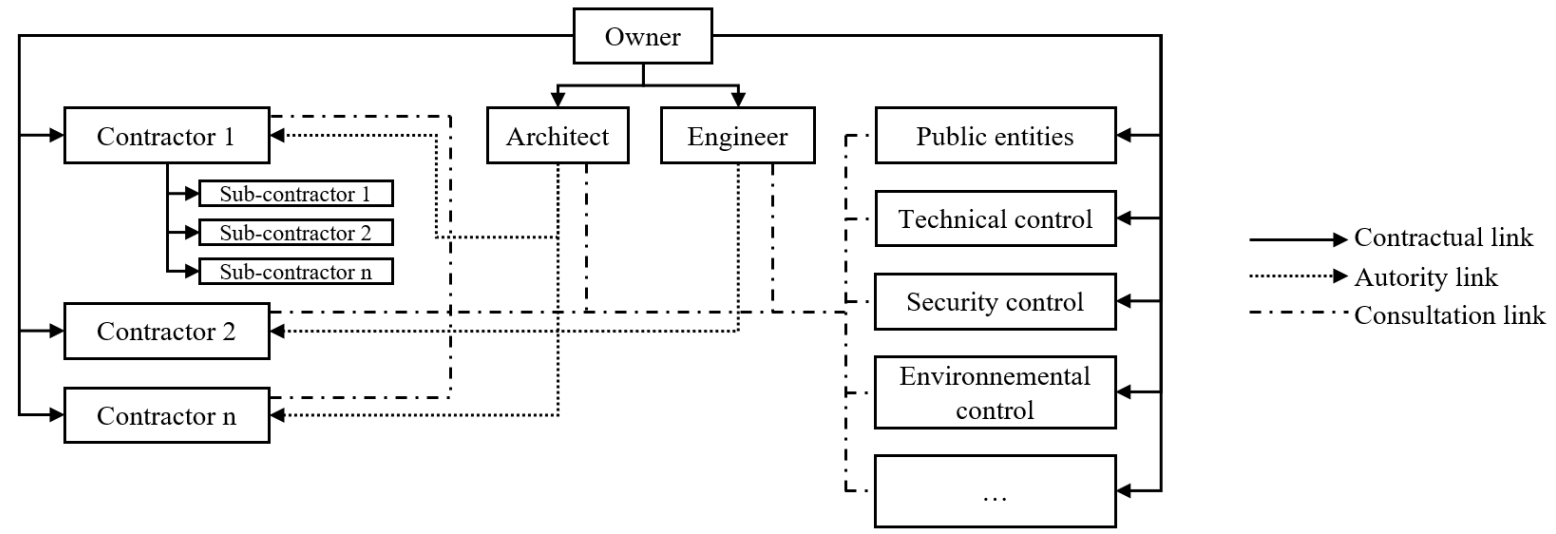

Figure 3. Link between stakeholders in a construction project (Raabe, 2002)

For the study, we need to restrain the number of actors. In terms of the sums of money involved, this relation is the most important (the construction company concentrates approximatively $90 \%$ of the cost of construction projects (UNCANS, 2017) and so this relation concentrates most of the conflicts. We therefor decide to focus on the relation between the Owner and the Contractor.

\subsubsection{Elaboration of the list of FAcT}

Our aim in the elaboration of the list of FAcT was to assure that no important item has been forgotten. As one of the authors can justify of 15 years in construction field, and about 10 years in management position we decide to use his own experience to build a first list of FAcT. We use two steps of interview of professionals to complete and to confirm it, as illustrated in Figure 4.

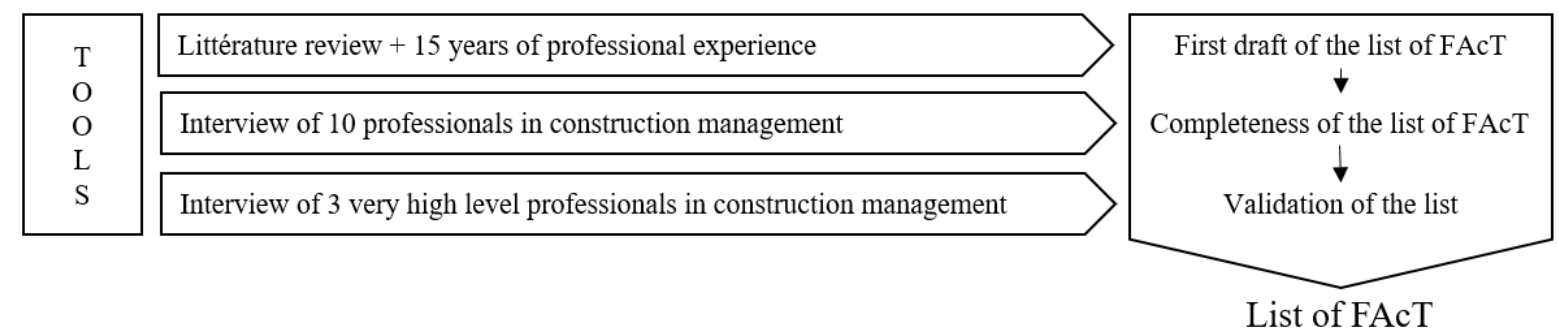

Figure 4. FAcT elaboration process

This process allows to set up a list of 139 FAcT, distributed in 79 Fears, 21 Attractiveness, 39 Temptations. To avoid bias, we cut human safety items, like, the fear to have injury, as we are studying relation between actors, we consider them not relevant in this study on contractual relation. The analysis of FAcT items based on the FAcT Mirror method brings a complementary point of view to the contractual view, it is an analysis of the human relationship which completes the mechanist view of the contrat.

Table 1. Non-exhaustive list of FAcT items (for example)

\begin{tabular}{|l|l|}
\hline \multicolumn{1}{|c|}{ Owner } & \multicolumn{1}{c|}{ Contractor } \\
\hline $\begin{array}{l}\text { Fear: to have underestimated the budget necessary to } \\
\text { carry out the project }\end{array}$ & $\begin{array}{l}\text { Fear to be held responsible for the delay of the } \\
\text { project }\end{array}$ \\
\hline Fear: to endure delay & Fear not to be paid by the Owner \\
\hline Attractiveness: to increase its production capacity & $\begin{array}{l}\text { Attractiveness: to increase the size of his customer } \\
\text { directory }\end{array}$ \\
\hline Attractiveness: to improve its production tool & $\begin{array}{l}\text { Attractiveness, for the Contractor, to carry out the } \\
\text { additional work for the Owner }\end{array}$ \\
\hline $\begin{array}{l}\text { Temptation to launch operations without having the } \\
\text { funding }\end{array}$ & $\begin{array}{l}\text { Temptation to hide information from the Owner } \\
\text { (delay order, breakdown suppliers' stock...) }\end{array}$ \\
\hline $\begin{array}{l}\text { Temptation, for the Owner, to pay companies with } \\
\text { delay to earn cash }\end{array}$ & $\begin{array}{l}\text { Temptation to use materials cheaper than those } \\
\text { required by the Owner }\end{array}$ \\
\hline
\end{tabular}




\subsubsection{Notation and classification of the FAcT}

In the aim to classify the FAcT items we need to make an evaluation of their importance. To reach this goal we decide to elaborate a survey. The survey consists in a questionnaire divided in three parts, a first short part about the quality of the respondent, a second short part about the qualification of the project we ask the respondent to consider and the third part which is the FAcT items notation part based on a Likert scale from 1 to 10 . The survey is long, the time necessary for a respondent to answer the 158 questions survey is between 20 and 30 minutes.

We broadcast the survey in 3 diverse ways. The first way was a diffusion on one author's direct professional network by email, the second consisted to use sponsorship principle, asking to peoples who have already answered to broadcast it to their network, and finally a diffusion on LinkedIn.

\subsection{Results of the survey and analysis processes}

\subsubsection{Validation of the results}

We obtain 45 answers on a total of 167 surveys sent, this led to a rate of participation of $26.95 \%$ in the period of August to September 2018. Taking into consideration the length and the complexity of the questionnaire, and in comparison with other similar study (Suprapto, Bakker and Mooi, 2015) this answer rate is good.

Among the 45 answers we had to reject two of them as it appears that the respondents clearly do not understand the exercise. Also, as control, the questionnaire had some redundant questions, the comparable results on these questions allow us to validate the quality of the answers collected.

Moreover, the questionnaire gives permission to respondent to add items and to give them a notation, it allows us to confirm the list.

\subsubsection{Homogeneity of the respondents}

We control the homogeneity of the respondents on three aspects, typology, quality, and experience. For typology we classified the respondent according to three types of group Owner, Contractor and Neutral, Owner (Owner and Engineers) represents $44 \%$ of respondent, Contractors are $40 \%$ of respondent, and Neutral group (independent expert, counsel) represents $16 \%$ of respondent, this group can work for Owner or for Contractor and has a reputation of independence.

The quality of the respondent is homogenous and go from young project manager to CEO. Also, the distribution of the number of years of experience of the respondent confirms the homogeneity of the group. The Table 2 sums up all of this data.

Table 2. Demographic

\begin{tabular}{llrr}
\hline Characteristic & Category & Number & Percentage \\
\hline Organisation type & Owner & 19 & $44,19 \%$ \\
& Contractor & 17 & $39,53 \%$ \\
& Consultant & 7 & $16,28 \%$ \\
\hline Position & CEO & 6 & $13,95 \%$ \\
& Project Director & 11 & $25,58 \%$ \\
& Project manager & 10 & $23,26 \%$ \\
& Deputy PM & 4 & $9,30 \%$ \\
& Other engineer & 12 & $27,91 \%$ \\
\hline
\end{tabular}

\begin{tabular}{llrr}
\hline Characteristic & Category & Number & Percentage \\
\hline Experience in the & $<5$ years & 3 & $6,98 \%$ \\
construction industry & 5 to 10 years & 12 & $27,91 \%$ \\
& 10 to 20 years & 15 & $34,88 \%$ \\
& 20 to 30 years & 10 & $23,26 \%$ \\
& 30 to 40 years & 3 & $6,98 \%$ \\
\hline Contract amount & <1million & 8 & $18,60 \%$ \\
& 1 to 5 millions & 6 & $13,95 \%$ \\
& 5 to 10 millions & 2 & $4,65 \%$ \\
& 10 to 50 millions & 15 & $34,88 \%$ \\
& 50 to 100 millions & 4 & $9,30 \%$ \\
& $>100$ millions & 8 & $18,60 \%$ \\
\hline
\end{tabular}

\subsection{Proposition of a method to analyse the results}

To analyse the results the next step of the FAcT Mirror ${ }^{\circledR}$ is the structuration of the data in unavoidable thematics. The process of structuration consists in sorting the items by average importance, picking the most important item and creating a first register where the item is placed, then picking-up the next important item in the list, if this item is linked to the first register created, then we place it in it, if not we create a new register. We follow this process (Figure 5) until all items are treated, the result is a creation of registers, which allows to formulate, for each register, an unavoidable thematic. We arrive 
to a total of eight unavoidable thematics, in order of apparition, Finance, Time, Communication (External), Quality, Contract, Claim, Human, Law, they are represented in the legend of Figure 6.

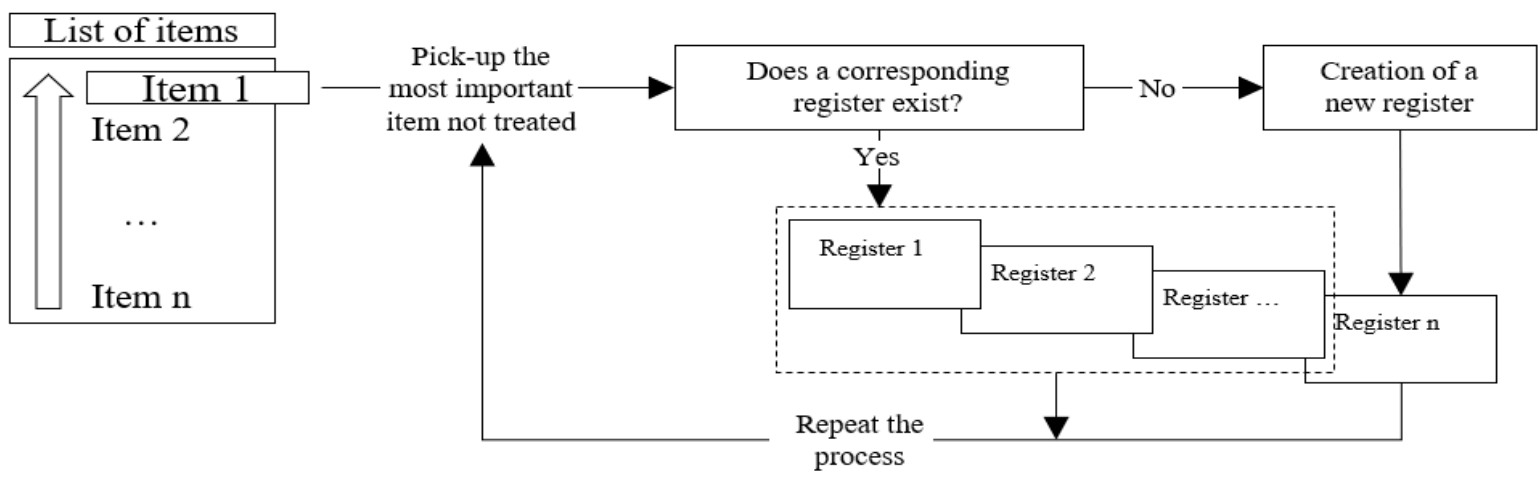

Figure 5. FAcT items classification process

We used the FAcT Mirror ${ }^{\circledR}$ Method to describe the global mindset of the stakeholders and, as in our case, the conflict is inherent to the relation and as the parties have opposed interests, the structuration of Fact Mirror ${ }^{\circledR}$ is not enough to analyse the data. We decided to take a step aside the FAcT Mirror ${ }^{\circledR}$ method and to have a look at the main differences between Owner and Contractor points of view and to question the consensus. In this phase we consider each item with two specific characteristics, the average importance given by all respondents, and the gap in notation between Owner and Contractor. The gap in notation is the difference in notation the owner gives with the notation the Contractor gives about one specific item. The gap allows us to understand what the vision of an actor on the other actor's item is.

Figure 6 gives a representation of the gap between Owner and Contractor in FAcT notation (Y axis) distributed by notation (X axis). As per example, we circle three items to help to understand the Figure 6. The item "A" is Contractor's Temptation to use cheaper material than the one required by the Owner. Here the importance of this item is average (5.72 over 10), but we see that the difference of perception is high between the actors, the Owner considers it as a very probable situation ( 7.74 over $10)$ when the Contractor considers it as a very unprobeable situation (3.65 over 10$)$. The item " $\mathrm{B}$ " is Contractor's Attractiveness to make benefits and item "C" is Contractor's Fear to hire illegal employees.

As a general observation on Figure 6 we see that items both with the highest and lowest level of importance, according to the respondent, are also corresponding with low gap level. The most important dissensus are situated on the item classified of middle importance, which is understandable, because it concerns items where Owners completely disagree with Contractors. 


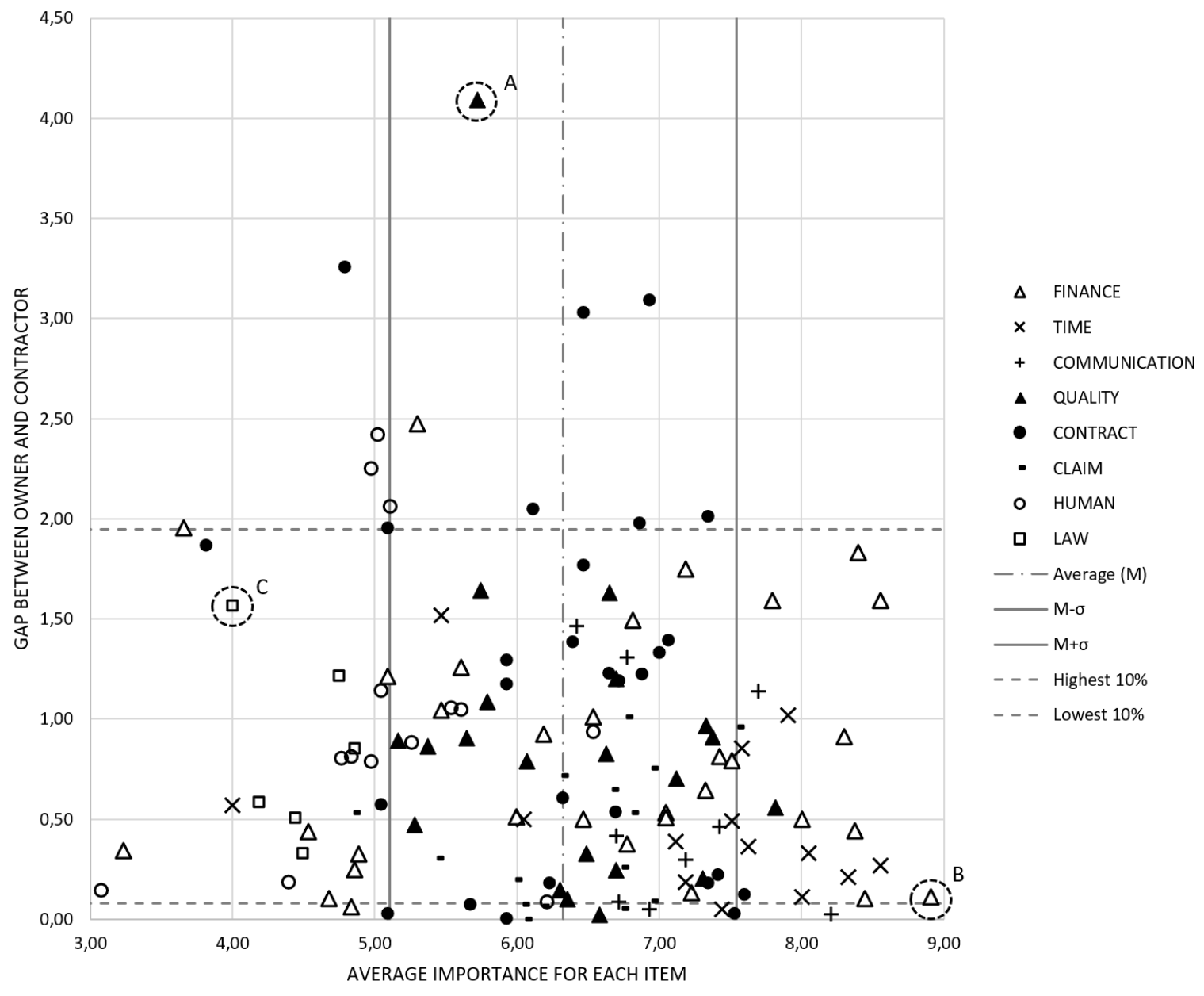

Figure 6. Gap between Owner and Contractor in FAcT notation distributed by notation

The delimitation between the different zones of the graph are of two types. After an examination of the distribution of the average notation given to the items it appears that it is coherent with a normal law, so we calculated a standard deviation $(\sigma)$. To discriminate the gap in notation, we arbitrarily chose to examine the highest and lowest $10 \%$.

Going deeper on the analysis of gap between Owner and Contractor notation, we note that the proportion of Owner's item is more important in the lowest gap of evaluation than in the highest gap and the proportion of Contractor's Temptation are the majority of bigger gap. Figure 7 represents the repartition of FAcT in four quartiles, the first quartile represents the $25 \%$ of the items with the lowest gap of notation between the Owner and the Contractor, the fourth quartile represents the $25 \%$ of the items with the highest gap of notation, in each quartile we quantify the repartition of the different types of items and we sort them by actor.

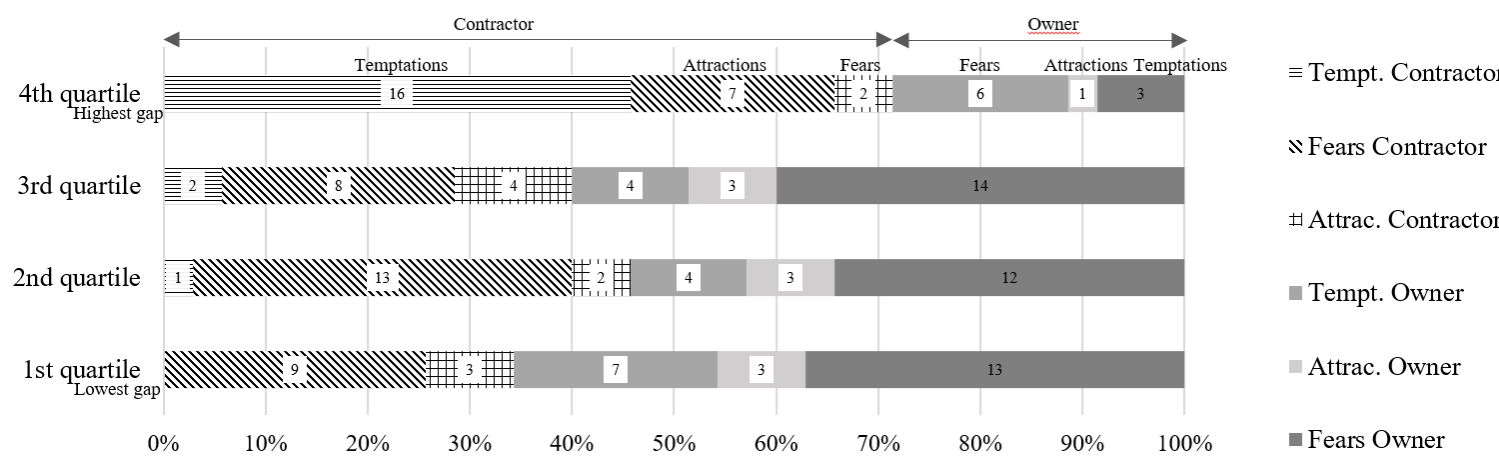

Figure 7. Repartition of FAcT by gap of notation

According to Figure 7, the repartition of type of items by quartiles shows that there is a correlation between the origins of the items and the gap of notation. As example, in the fourth quartile, we can see that $71.4 \%$ of FAcT items have for origin the Contractor and the ratio is inversed in the first quartile 
where $65.7 \%$ of the FAcT items in this quartile come from the Owner. Moreover, the quartile concerning the biggest gaps in notation concentrate $84 \%$ of the total number of Contractor's Temptations.

On the next part we give interpretation of the factual results we obtain.

\subsection{Interpretations of the results}

We interpret the results on three aspects, the first one concerns the possibility to see patterns in the type of items and the average notation, the second aspect concerns the highest gap in notation and the third aspect treats the repartition of Owners items and Contractors items in the gap of notation.

The items with the highest average importance (20 items; 8F; 4A; 8T) correspond to elements in link with QCD (Quality Cost Delivery) management, here represented by the thematic Quality, Finance, Delays, and, one item is about the public image of the actor. This result is not surprising, it shows that actors are aware of the main goal of their project and respective organization. Even if in the last decades, the concept of QCD have been amended, it stays a fundamental concept of project management.

According to the items with the lowest importance (29 items; 22F, 0A, 7T), most of these items are related to fears to non-respecting basic business or legal processes. As an example, Fears like nonrespecting the law or Fears of changes in the law which could affects the project, in France this aspect is not one of the main preoccupations of the stakeholders, the country is stable, changes in the law are predictive. Another example is the Fear of having illegal employee on the construction site, one answer is that companies already have numerous processes to protect them to act wrongly on this matter, another possibility could be that the risk of employing illegal worker is not perceived as an important one.

About the item with highest gap between Owner and Contractor point of view (11 items; 2F, 0A, 9T), it concerns items for which it is difficult to evaluate the fulfilment or which it is difficult to find evidence of a non-desired behaviour. Most of them are items of Temptation from the Contractor.

Concerning the Figure 7, if we suppose that an actor is the best assessor of his own feelings, the fact that most of FAcT items with the lowest gap are Owner's FAcT and that most of FAcT items with the highest gap are Contractor's FAcT suggests that Contractor has a better understanding of Owner's feelings. Another possibility could be that Contractor may be reluctant to evaluate their temptation correctly.

\subsection{Evaluation of the results}

To evaluate the results of the study we use interviews of professionals and presentations to group of professionals:

- Interviews with professionals who answered the survey in which we present the results and the conclusion.

- Interviews with professionals who did not answer the survey to whom we present the study, the results, and the conclusion.

- Presentation of the study, the results, and the conclusions to group of professionals, this allows to obtain debates.

Along these interviews and presentations, we keep a track of the reaction to produce a verbatim.

Also, to verify the genericity of the result, we organise workshops in different companies of different industrial sectors. The evaluation of the results is an ongoing work, the results can be presented in ICED for forward discussions.

\section{CONCLUSIONS AND FUTURE WORKS}

Along this paper we explore the diverse ways to analyse the relation between actors. Our paper shows that the difference of perception from the different actors is rarely studied. We choose the FAcT Mirror ${ }^{\circledR}$ method which allows us to study the difference of perception of actors toward each other in a given situation, here in the construction industry. We use this method to structure a survey about the Fears, the Attractiveness, and the Temptation of treason actors can have in their relation. We decided to do a step aside the method to explore the gap between actors' perception about the other actor's feeling.

Our survey is the first to focus on the differences of perception from the actors on the specific feeling each can have about himself, the project or the other actor. The added value of our paper is that our results allow us and the actors of a project to have a better understanding of the relation between Owners and Contractors on a construction project and the supposed thoughts one actor can have toward the other one or the project. 
The gap of notation of items is a concern, the two hypothesis we formulate, the contractor has a better knowledge of Owners and Contractor may be reluctant to evaluate honestly his temptation, need to be deepened. We make the supposition that there are complementary, this is an assumption we need to verify. Also, to understand the roots of these differences of perception should allow us to find link with production and project control processes involved.

We also want to confirm the findings concerning actors' behaviour towards law, it would be particularly useful to understand this aspect of actor's behaviour and to conclude if we can reach the same results in a country with a different level of maturity of their legal system.

The next steps will be to enlarge these studies to other construction project's context and to compare to findings in literature.

\section{REFERENCES}

Thesis: Brunet, A. (2005), "UNIVERSITE PANTHEON-ASSAS ( PARIS II ) INCOMPLETUDE CONTRACTUELLE Daniel VITRY, Professeur à l”, Université de Paris II - Panthéon-Assas Eric BROUSSEAU, Professeur à 1 ' Université de Paris X - Nanterre, rapporteur', (PARIS II).

Le Cardinal, G. et al. (2001), "Intervention methodology for complex problems: The FAcT-Mirror method", European Journal of Operational Research, Vol. 132 No. 3, pp. 694-702. http://doi.org/10.1016/S0377$2217(00) 00178-8$.

Book: Le Cardinal, G., Guyonnet, J.F. and Pouzoullic, B. (1997), "La Dynamique de la Confiance - Construire la coopération dans les projets complexes". DUNOD.

Dyer, J.H. (1997), "Effective interim collaboration: how firms minimize transaction costs and maximise transaction value", Strategic Management Journal, Vol. 18 No. 7, pp. 535-556. http://doi.org/10.1002/(SICI)1097-0266(199708)18:7<535::AID-SMJ885>3.3.CO;2-Q.

Kartam, S. (1999), "Generic Methodology for Analyzing Delay Claims", Journal of Construction Engineering \& Management, Vol. 125 No. 6, pp. 409-419. http://doi.org/10.1061/(ASCE)0733-9364(1999)125:6(409).

Levin, P. (1998), "Construction contract claim, changes \& dispute resolution”, in. Reston.

$\mathrm{Lu}$, P. et al. (2015), "The effectiveness of contractual and relational governances in construction projects in China”, International Journal of Project Management. Elsevier B.V., Vol. 33 No. 1, pp. 212-222. http://doi.org/10.1016/j.ijproman.2014.03.004.

Lumineau, F., Fréchet, M. and Puthod, D. (2011), "An organizational learning perspective on the contracting process”, Strategic Organization, Vol. 9 No. 1, pp. 8-32. http://doi.org/10.1177/1476127011399182.

Mitropoulos, P. and Howell, G. (2001), "Model for Understanding, Preventing and Resolving Project Disputes", Journal of Construction Engineering and Management, Vol. 127 No. 3, pp. 223-231. http://doi.org/10.1061/(ASCE)0733-9364(2001)127:3(223).

Book: Morin, E. (2005), "Introduction à la pensée complexe". Edited by Seuil, C.. Points Essais. Paris.

Book: Morin, E. (2008), "On Complexity", Hampton Press.

Poppo, L. and Zenger, T. (2002), "Do formal contracts and relational governance function as substitutes or complements?", Strategic Management Journal, Vol. 23 No. 8, pp. 707-725. http://doi.org/10.1002/smj.249.

Reuer, J. and Arino, A. (2017), "Strategic alliance contracts: dimensions and determinants of contractual complexity”, Information (Japan), Vol. 20 No. 1, pp. 397-403. http://doi.org/10.1002/smj.

Rooke, J., Seymour, D. and Fellows, R. (2004), "Planning for claims: An ethnography of industry culture", Construction Management and Economics, Vol. 22 No. 6, pp. 655-662. http://doi.org/10.1080/014461904200026324.

Book: SCL (2017), "Society of Construction Law Delay and Disruption 2nd edition February 2017". Available at: www.scl.org.uk.

Suprapto, M., Bakker, H.L.M. and Mooi, H.G. (2015), "Relational factors in owner-contractor collaboration: The mediating role of teamworking", International Journal of Project Management. Elsevier Ltd and IPMA, Vol. 33 No. 6, pp. 1347-1363. http://doi.org/10.1016/j.ijproman.2015.03.015.

Report: UNCANS (2017), "Observatoire des coûts de la construction".

Book: Watzlawick, P., Helmick-Beavin, J. and Jackson, D.D.A. (1967), "Pragmatics of Human Communication: A Study of Interactional Patterns", Pathologies and Paradoxes. 1St edn. Norton.

Wong, W.K. et al. (2008), "A framework for trust in construction contracting", International Journal of Project Management. Elsevier Ltd and IPMA, Vol. 26 No. 8, pp. 821-829. http://doi.org/10.1016/j.ijproman.2007.11.004.

Yiu, K.T.W. and Cheung, S.O. (2006), "A catastrophe model of construction conflict behavior", Building and Environment, Vol. 41 No. 4, pp. 438-447. http://doi.org/10.1016/j.buildenv.2005.01.007.

Thesis: Zimmer, B. (2012), "Structuration d'un cluster d'innovation: Application aux projets d'innovation dans une grappe d'entreprises en gérontechnologie", Thèse de Doctorat en génie industriel, Centrale Paris. 